\title{
Influence of reaction channel on the isomeric cross-section ratio
}

\author{
By S. M. Qaim ${ }^{1, *}$, S. Sudár ${ }^{1,2}$ and A. Fessler ${ }^{1, \dagger}$ \\ ${ }^{1}$ Institut für Nuklearchemie, Forschungszentrum Jülich GmbH, 52425 Jülich, Germany \\ 2 Institute of Experimental Physics, Debrecen University, 4010 Debrecen, Hungary
}

Dedicated to Prof. Dr. Dr. h.c. Julius Csikai on his 75th birthday

(Received March 4, 2005; accepted in revised form June 21, 2005)

Reaction channel / Isomeric cross-section ratio / Nuclear model calculation

Summary. The influence of reaction channel on the isomeric cross-section ratio was investigated by analysing the experimental data on the reactions ${ }^{52} \mathrm{Cr}(p, n)^{52 \mathrm{~m}, \mathrm{~g}} \mathrm{Mn}$, ${ }^{52} \mathrm{Cr}\left({ }^{3} \mathrm{He}, t\right){ }^{52 \mathrm{~m}, \mathrm{~g}} \mathrm{Mn},{ }^{54} \mathrm{Fe}(d, \alpha){ }^{52 \mathrm{~m}, \mathrm{~g}} \mathrm{Mn},{ }^{54} \mathrm{Fe}(n, t){ }^{52 \mathrm{~m}, \mathrm{~g}} \mathrm{Mn}$ and ${ }^{54} \mathrm{Fe}\left({ }^{3} \mathrm{He}, \alpha p\right){ }^{52 \mathrm{~m}, \mathrm{~g}} \mathrm{Mn}$ over the incident particle energy range extending up to $35 \mathrm{MeV}$. The influence is most pronounced when the channels differ widely, for example $(p, n)$ and $\left({ }^{3} \mathrm{He}, t\right)$ processes, i.e. when the reaction mechanisms are different. The nuclear model calculational code EMPIRE-II described the isomeric cross-section ratio rather well in the case of a simple nucleon emission reaction, but not when complex reaction channels were involved.

\section{Introduction}

Studies of isomeric cross sections are of considerable fundamental interest. It has been shown [1] that the isomeric cross-section ratio is primarily governed by the spins of the two levels involved, rather than their separation and excitation energies. Furthermore, through detailed investigations on the formation of ${ }^{73 \mathrm{~m}, \mathrm{~g}} \mathrm{Se}$ in six nuclear reactions [2], ${ }^{58 \mathrm{~m}, \mathrm{~g}} \mathrm{Co}$ in seven nuclear reactions [3] and ${ }^{94 \mathrm{~m}, \mathrm{~g}} \mathrm{Tc}$ in three nuclear processes [4], involving different combinations of target, projectile and ejectile, effects of level structure of the product nucleus, angular momentum distribution in preequilibrium decay, branching ratios of $\gamma$ rays from discrete levels, etc. have been studied. The influence of the reaction channel on the isomeric cross-section ratio in neutron induced reactions was also investigated but the result was rather inconclusive [5,6]. A common feature of all those studies was that in the deexcitation of the compound nucleus, only nucleons, or occasionally an $\alpha$-particle, were involved. It was now considered worthwhile to investigate more complex reactions like $(n, t)$, $\left({ }^{3} \mathrm{He}, t\right)$ and $\left({ }^{3} \mathrm{He}, \alpha p\right)$, and to compare the resulting isomeric cross-section ratios with those in simple reactions, like $(p, n)$, etc. The results might shed some light on the

\footnotetext{
*Author for correspondence (E-mail: s.m.qaim@fz-juelich.de).

${ }^{\dagger}$ Now at Institute for Reference Materials and Measurements (IRMM), 2440 Geel, Belgium
}

possible influence of the reaction channel on the isomeric cross-section ratio. We chose to study the isomeric pair ${ }^{52 \mathrm{~m}, \mathrm{~g}} \mathrm{Mn}$ in ${ }^{52} \mathrm{Cr}(p, n)-,{ }^{52} \mathrm{Cr}\left({ }^{3} \mathrm{He}, t\right)-,{ }^{54} \mathrm{Fe}(d, \alpha)-,{ }^{54} \mathrm{Fe}(n, t)-$ and ${ }^{54} \mathrm{Fe}\left({ }^{3} \mathrm{He}, \alpha p\right)$-reactions. The metastable state has a spin $2^{+}$and the ground state $6^{+}$. Both of them decay by EC + $\beta^{+}$emission, the metastable state almost independently to ${ }^{52} \mathrm{Cr}$. All the measurements were done radiochemically. For an understanding of the reaction mechanism, nuclear model calculations were performed using the recently developed code EMPIRE-II.

\section{Experimental}

For the measurement of the excitation function of each charged-particle induced reaction the standard stackedfoil technique was used. Thin samples were prepared by electrolytic deposition. Irradiations were done at the compact cyclotron CV 28 at Jülich, and the beam currents were measured via monitor reactions. The radioactivity of the two isomeric states was determined using HPGe detector $\gamma$-ray spectrometry. Due to relatively low cross sections for the formation of ${ }^{52 \mathrm{~g}} \mathrm{Mn}$ at low incident particle energies, the product was radiochemically separated. Details on the ${ }^{52} \mathrm{Cr}\left({ }^{3} \mathrm{He}, t\right){ }^{52 \mathrm{~m}, \mathrm{~g}} \mathrm{Mn},{ }^{52} \mathrm{Cr}(p, n)^{52 \mathrm{~m}, \mathrm{~g}} \mathrm{Mn}$ and ${ }^{54} \mathrm{Fe}(d, \alpha)^{52 \mathrm{~m}, \mathrm{~g}} \mathrm{Mn}$ reactions are given elsewhere [7-9]. The ${ }^{54} \mathrm{Fe}\left({ }^{3} \mathrm{He}, \alpha p\right){ }^{52 \mathrm{~m}, \mathrm{~g}} \mathrm{Mn}$ process was studied using the techniques similar to those described earlier [7-9] and the results are given in [10].

Studies on the ${ }^{54} \mathrm{Fe}(n, t)^{52 \mathrm{~m}, \mathrm{~g}} \mathrm{Mn}$ reaction involved the use of three neutron sources: (a) $d / t$ neutron generator at Jülich [11], (b) $d / t$ neutron source at a Van de Graaff machine at Geel [10], (c) $d /$ Be breakup neutron source at an intermediate energy cyclotron JULIC at Jülich [12]. In each case the activation technique was used. Details of those older measurements have been described earlier [10-12].

Since the cross sections of the two isomeric states involved were measured via independent experiments, the total uncertainties associated with the isomeric cross-section ratios were slightly higher than those with the individual cross sections. To the experminental cross-section ratios in the charged-particle induced reactions we assign uncertainties of 16 to $18 \%$ and to those in the neutron-induced process 25 to $30 \%$. 


\section{Nuclear model calculations}

The isomeric cross-section ratios were calculated for the $\left.{ }^{52} \mathrm{Cr}(p, n){ }^{52 \mathrm{~m}, \mathrm{~g}} \mathrm{Mn},{ }^{52} \mathrm{Cr}\left({ }^{3} \mathrm{He}, t\right)\right)^{52 \mathrm{~m}, \mathrm{~g}} \mathrm{Mn},{ }^{54} \mathrm{Fe}(d, \alpha){ }^{52 \mathrm{~m}, \mathrm{~g}} \mathrm{Mn}$, ${ }^{54} \mathrm{Fe}(n, t){ }^{52 \mathrm{~m}, \mathrm{~g}} \mathrm{Mn}$ and ${ }^{54} \mathrm{Fe}\left({ }^{3} \mathrm{He}, \alpha p\right){ }^{52 \mathrm{~m}, \mathrm{~g}} \mathrm{Mn}$ reactions using the EMPIRE-II (version 2.19 Lodi) code developed by Herman et al. [13]. This code makes use of the Hauser-Feshbach model (including the width fluctuation correction (HRTW)) for the statistical part and the exciton model for the precompound part of a nuclear reaction. For input parameters, the standard library was used; it included the nuclear masses, ground state deformations, discrete levels and decay schemes, level densities, moments of inertia (MOMFIT), and $\gamma$-ray strength functions.

The particle transmission coefficients for both the exciton and Hauser-Feshbach formalisms were generated via the spherical optical model using the computer code SCAT $2[14,15]$ and a set of global parameters: for neutrons and protons of Koning and Delaroche [16], and for alpha particles of McFadden and Satchler [17]. For calculations on the reactions ${ }^{54} \mathrm{Fe}\left({ }^{3} \mathrm{He}, \alpha p\right){ }^{52 \mathrm{~m}, \mathrm{~g}} \mathrm{Mn},{ }^{54} \mathrm{Fe}(d, \alpha)^{52 \mathrm{~m}, \mathrm{~g}} \mathrm{Mn}$, ${ }^{54} \mathrm{Fe}(n, t){ }^{52 \mathrm{~m}, \mathrm{~g}} \mathrm{Mn}$ and ${ }^{52} \mathrm{Cr}\left({ }^{3} \mathrm{He}, t+d n\right)^{52 \mathrm{~m}, \mathrm{~g}} \mathrm{Mn}$ only the Hauser-Feshbach (HF) model was used. For the reaction ${ }^{52} \mathrm{Cr}(p, n)^{52 \mathrm{~m}, \mathrm{~g}} \mathrm{Mn}$, on the other hand, the HF + MSC + MSD model as well as the HF + DEGAS exciton model [18] with angular momentum conservation and gamma emission, were used. For the level densities, the dynamic approach of the EMPIRE-II was applied with the formalism of the superfluid model (BCS) below the critical excitation energies, and the Fermi gas model above the critical energy. Unfortunately the EMPIRE code could handle the preequilibrium processes only in the neutron and proton channels.

\section{Results and discussion}

\subsection{Comparison of experimental and theoretical data}

The experimental isomeric cross-section ratios for the pair ${ }^{52 \mathrm{~m}, \mathrm{~g}} \mathrm{Mn}$ in the five investigated reactions are shown separately in Figs. 1 to 5. The calculated data are also given in each respective diagram. The best agreement between experiment and theory was obtained in the case of the reaction ${ }^{52} \mathrm{Cr}(p, n)^{52 \mathrm{~m}, \mathrm{~g}} \mathrm{Mn}$ (Fig. 1) where the calculation was done by the $\mathrm{HF}+$ exciton model. Somewhat similar results were obtained up to $20 \mathrm{MeV}$ while using the $\mathrm{HF}+\mathrm{MSC}+$ MSD model; beyond $20 \mathrm{MeV}$, however, the calculated results using this formalism were consistenly lower than the experimental data as well as the calculated data from the $\mathrm{HF}+$ excitation model. In the case of the other four reactions, due to the emission of complex particles, only HF calculations could be done. For the reaction ${ }^{54} \mathrm{Fe}(d, \alpha)^{52 \mathrm{~m}, \mathrm{~g}} \mathrm{Mn}$ the calculated results are lower and for ${ }^{54} \mathrm{Fe}\left({ }^{3} \mathrm{He}, \alpha p\right){ }^{52 \mathrm{~m}, \mathrm{~g}} \mathrm{Mn}$ considerably lower than the experimental data, though the shapes of the experimental and calculated curves are similar (Figs. 2 and 3). The results show that the HF method alone (i.e. neglecting the precompound contribution) underestimates the contribution of the $2^{+}$excited state in comparison to the $6^{+}$ground state. The calculated data for the ${ }^{54} \mathrm{Fe}(n, t){ }^{52 \mathrm{~m}, \mathrm{~g}} \mathrm{Mn}$ reaction are more or less in agreement with the experimental data in the energy range of 19 to $23 \mathrm{MeV}$ but differ considerably near the threshold of the reaction

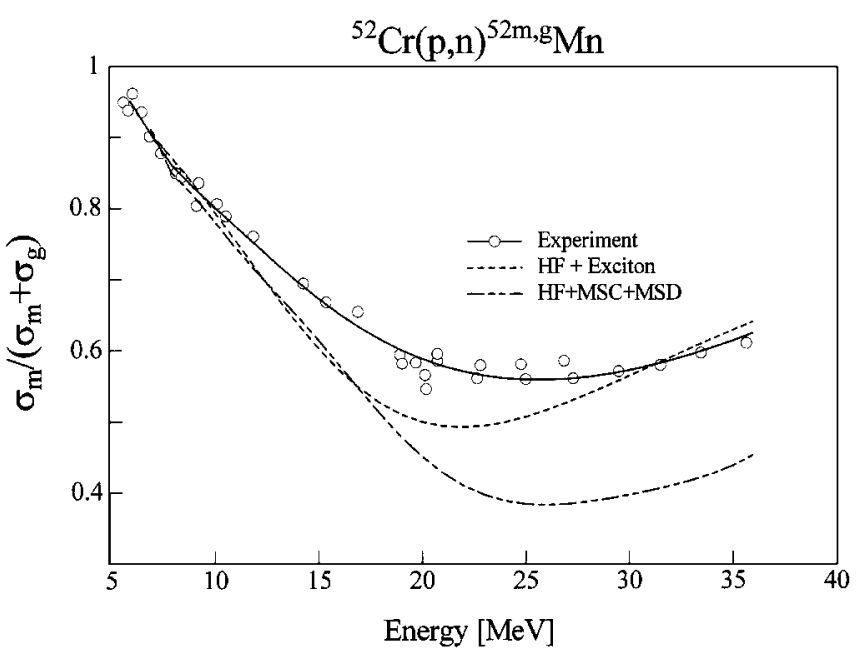

Fig. 1. Experimental and theoretical isomeric cross-section ratios for the isomeric pair ${ }^{52 \mathrm{~m}, \mathrm{~g}} \mathrm{Mn}$ formed in the ${ }^{52} \mathrm{Cr}(p, n)$-reaction, plotted as a function of the incident proton energy. The experimental data are from [8].

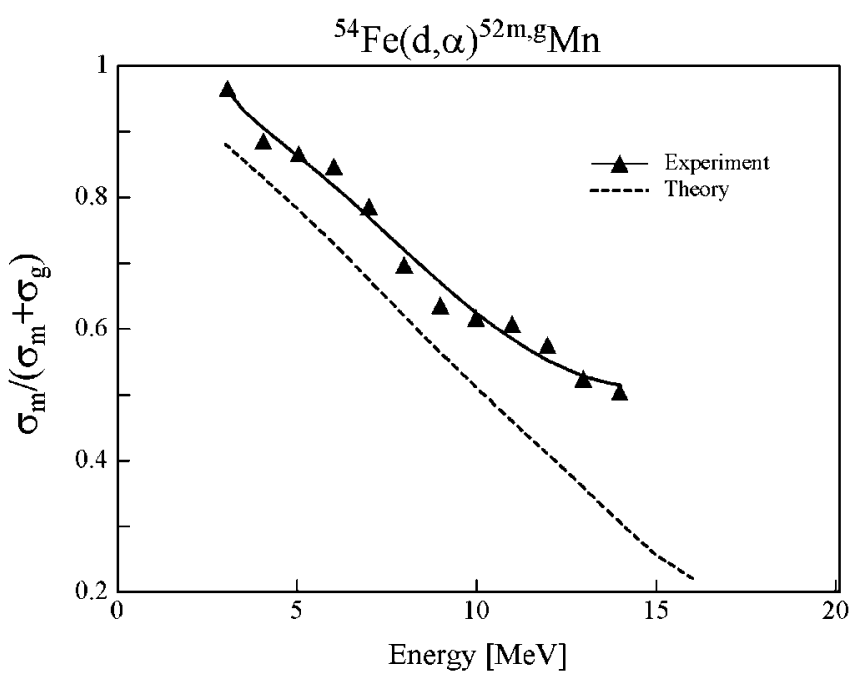

Fig. 2. Experimental and theoretical isomeric cross-section ratios for the isomeric pair ${ }^{52 \mathrm{~m}, \mathrm{~g}} \mathrm{Mn}$ formed in the ${ }^{54} \mathrm{Fe}(d, \alpha)$-reaction, plotted as a function of the incident deuteron energy. The experimental data are from [9].

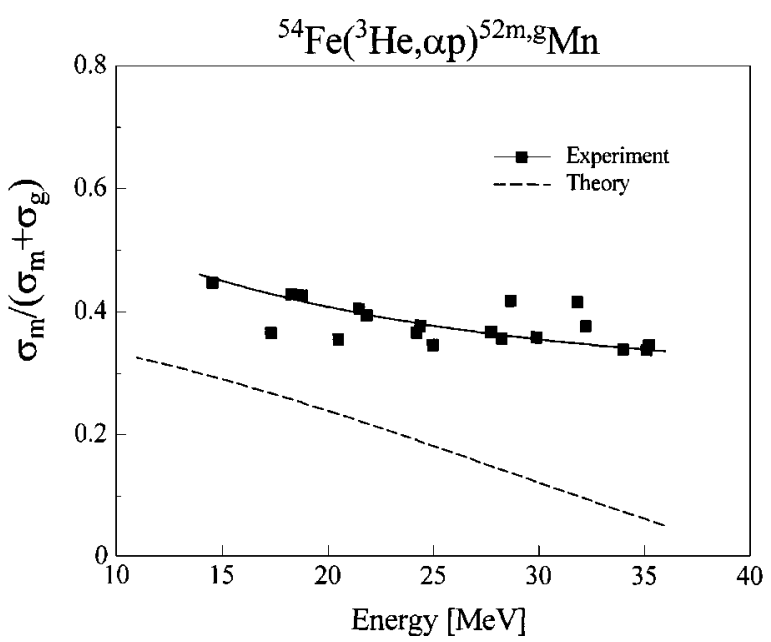

Fig. 3. Experimental and theoretical isomeric cross-section ratios for the isomeric pair ${ }^{52 \mathrm{~m}, \mathrm{~g}} \mathrm{Mn}$ formed in the ${ }^{54} \mathrm{Fe}\left({ }^{3} \mathrm{He}, \alpha p\right)$-reaction, plotted as a function of the incident ${ }^{3} \mathrm{He}$-particle energy. The experimental data are from [10]. 


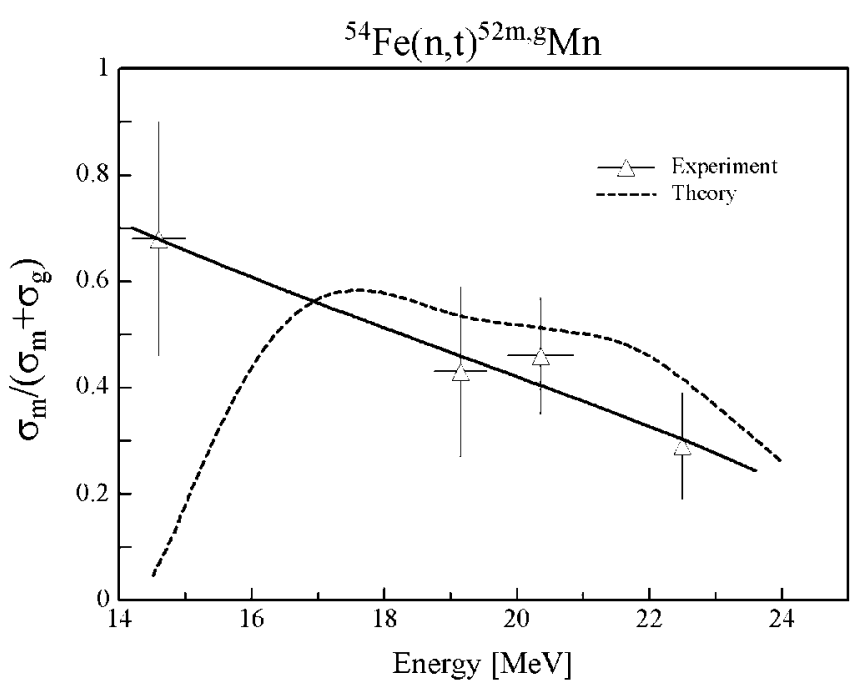

Fig. 4. Experimental and theoretical isomeric cross-section ratios for the isomeric pair ${ }^{52 \mathrm{~m}, \mathrm{~g}} \mathrm{Mn}$ formed in the ${ }^{54} \mathrm{Fe}(n, t)$-reaction, plotted as a function of the incident neutron energy. The experimental data are from [10-12]. Considering the large certainties involved, the data point at $14.6 \mathrm{MeV}$ [11] has been slightly lowered. The value at $22.5 \mathrm{MeV}$ has to be regarded as a rough estimate since it refers to a $53 \mathrm{MeV} \mathrm{d} / \mathrm{Be}$ breakup neutron spectrum [12].

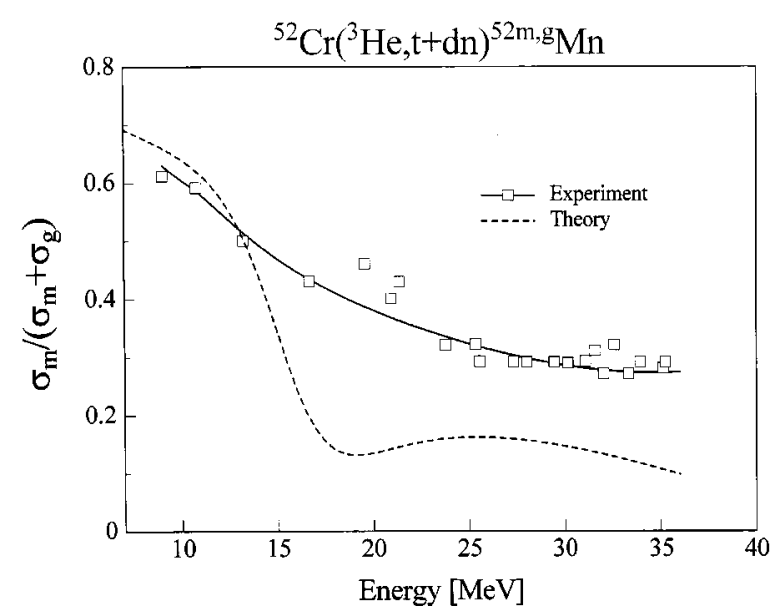

Fig. 5. Experimental and theoretical isomeric cross-section ratios for the isomeric pair ${ }^{52 \mathrm{~m}, \mathrm{~g}} \mathrm{Mn}$ formed in the ${ }^{52} \mathrm{Cr}\left({ }^{3} \mathrm{He}, t+d n\right)$-reaction, plotted as a function of the incident ${ }^{3} \mathrm{He}$-particle energy. The experimental data are from [7].

(Fig. 4). Apparently the contribution of the low-spin isomer is drastically underestimated near the threshold region. Also the calculated data for the ${ }^{52} \mathrm{Cr}\left({ }^{3} \mathrm{He}, t\right)^{52 \mathrm{~m}, \mathrm{~g}} \mathrm{Mn}$ process show a rather strange behaviour; there is good agreement with the experimental data till about $15 \mathrm{MeV}$, thereafter the calculation shows a sudden decrease and the values remain low as compared to the experimental data till the maximum investigated energy (Fig. 5). This reaction constitutes anyway a special case since it may involve a charge exchange direct process or real emission of $t, d n, p 2 n, 2 n p$ or $n p n$ entities.

The foregoing discussion shows that the theory can reproduce the isomeric cross-section ratio over a wide energy range only in the case of simple nucleon emission reactions whereas for more complex reactions the deviations between experiment and theory are relatively large. In the latter case, possibly direct interactions make

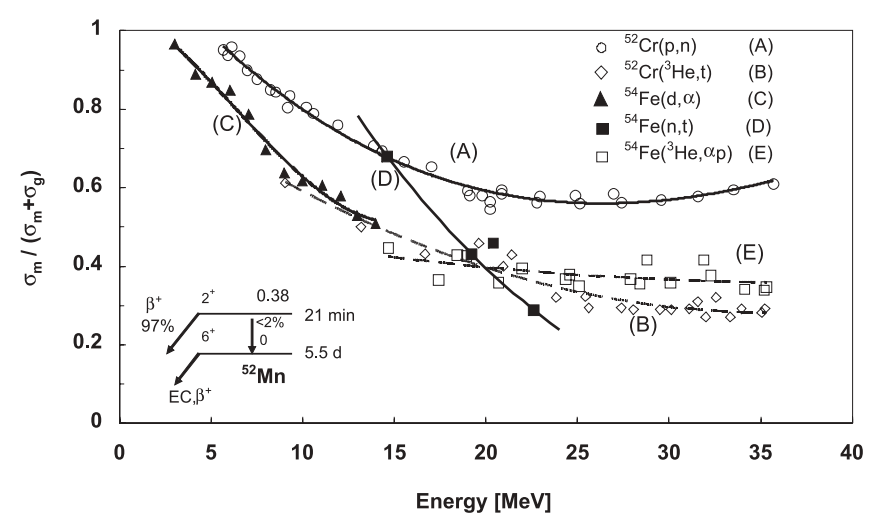

Fig. 6. Experimental isomeric cross-section ratios for the formation of ${ }^{52 \mathrm{~m}, \mathrm{~g}} \mathrm{Mn}$ in several nuclear reactions [7-12], plotted as a function of the incident particle energy.

significant contributions which are not included in the calculations.

The experimental results given in Figs. 1 to 5 also confirm the important role of the spins of the two states involved. The cross section of the low-spin isomer in comparison to that of the high-spin ground state decreases with the increasing incident projectile energy.

\subsection{Effect of reaction channel}

All the experimental isomeric cross-section ratios were plotted against the incident projectile energy and the results are shown in Fig. 6. For each reaction, initially the ratio decreases, but becomes almost constant at high excitation energies. It is interesting to note that the $(p, n)$ and $\left({ }^{3} \mathrm{He}, t\right)$ reactions (curves $\mathrm{A}$ and $\mathrm{B}$ ) occur on the same target nucleus and the product studied is also the same. The same is true for the $(d, \alpha),(n, t)$ and $\left({ }^{3} \mathrm{He}, \alpha p\right)$ reactions (curves $\mathrm{C}$, $\mathrm{D}$ and $\mathrm{E})$. The magnitudes of the isomeric cross-section ratios, however, differ appreciably. From the observed trends it is concluded that the reaction channel affects the isomeric cross-section ratio considerably, particularly when the channels differ widely, e.g. $(p, n)$ and $\left({ }^{3} \mathrm{He}, t\right)$ processes.

\section{Conclusion}

The isomeric cross-section ratio for the isomeric pair ${ }^{52 \mathrm{~m}, \mathrm{~g}} \mathrm{Mn}$ is described well using the EMPIRE-II calculational code in the case of a simple nucleon emission reaction, e.g. $(p, n)$. For more complex reaction channels, like $\left({ }^{3} \mathrm{He}, t\right)$ or $\left({ }^{3} \mathrm{He}, \alpha p\right)$, the calculated ratio is too low as compared to the experimental values, suggesting that contributions of direct interactions are rather high. A consideration of all the available experimental data showed that the effect of reaction channel is most pronounced when the channels differ widely, e.g. $(p, n)$ and $\left({ }^{3} \mathrm{He}, t\right)$ processes, which involve the same target nucleus and the same product isomeric pair but, presumably, very different reaction mechanisms.

Acknowledgment. We thank Prof. H. H. Coenen for his support of this work, and the operators of the compct cyclotron at Jülich as well as the Van de Graaff machine at Geel, for performing the irradiations. 


\section{References}

1. Qaim, S. M.: Recent developments in the study of isomeric cross sections. In: Proceedings of the International Conference on Nuclear Data for Science and Technology. (Dickens, J. K., ed.) American Nuclear Society Inc., LaGrange Park (1994) p. 186.

2. Qaim, S. M., Mushtaq, A., Uhl, M.: Isomeric cross-section ratio for the formation of ${ }^{73 \mathrm{~m}, \mathrm{~g}} \mathrm{Se}$ in various nuclear reactions. Phys. Rev. C 38, 645 (1988).

3. Sudár, S., Qaim, S. M.: Isomeric cross-section ratio for the formation of ${ }^{58 \mathrm{~m}, \mathrm{~g}} \mathrm{Co}$ in neutron, proton, deuteron and $\alpha$-particle induced reactions in the energy region up to $25 \mathrm{MeV}$. Phys. Rev. C 53, 2885 (1996).

4. Strohmaier, B., Fassbender, M., Qaim, S. M.: Production cross sections of ground and isomeric states in the reaction system ${ }^{93} \mathrm{Nb}+{ }^{3} \mathrm{He},{ }^{92} \mathrm{Mo}+\alpha$ and ${ }^{94,95} \mathrm{Mo}+p$. Phys. Rev. C 56, 2654 (1997).

5. Birn, I.-G., Strohmaier, B., Freiesleben, H., Qaim, S. M.: Isomeric cross-section ratios for the formation of ${ }^{75 \mathrm{~m}, \mathrm{~g}} \mathrm{Ge}$ in $(n, p),(n, a)$ and $(n, 2 n)$ reactions from 6 to $15 \mathrm{MeV}$. Phys. Rev. C 52, 2546 (1995).

6. Nesaraja, C. D., Sudár, S., Qaim, S. M.: Cross sections for the formation of ${ }^{69 \mathrm{~m}, \mathrm{~g}} \mathrm{Zn}$ and ${ }^{71 \mathrm{~m}, \mathrm{~g}} \mathrm{Zn}$ in neutron induced reactions near their thresholds: Effect of reaction channel on the isomeric crosssection ratio. Phys. Rev. C 68, 024603 (2003).

7. Fessler, A., Alfassi, Z. B., Qaim, S. M.: Excitation functions of ${ }^{3} \mathrm{He}$-particle induced nuclear reactions on natural chromium: possibilities of production of ${ }^{52} \mathrm{Fe},{ }^{53} \mathrm{Fe}$ and ${ }^{52} \mathrm{Mn}$ for medical use. Radiochim. Acta 65, 207 (1994).
8. Klein, A. T. J., $\quad$ Rösch, F., Qaim, S. M.: Investigation of $\left.{ }^{50} \mathrm{Cr}(d, n)\right)^{51} \mathrm{Mn}$ and $\left.{ }^{n a t} \mathrm{Cr}(p, x)\right)^{51} \mathrm{Mn}$ processes with respect to the production of the positron emitter ${ }^{51} \mathrm{Mn}$. Radiochim. Acta 88, 253 (2000).

9. Zaman, M. R., Spellerberg, S., Qaim, S. M.: Production of ${ }^{55} \mathrm{Co}$ via the ${ }^{54} \mathrm{Fe}(d, n)$-process and excitation functions of ${ }^{54} \mathrm{Fe}(d, t){ }^{53} \mathrm{Fe}$ and ${ }^{54} \mathrm{Fe}(d, \alpha){ }^{52 \mathrm{~m}} \mathrm{Mn}$ reactions from threshold up to 13.8 MeV. Radiochim. Acta 91, 105 (2003).

10. Fessler, A.: Activation cross sections and isomeric cross-section ratios in neutron induced reactions on $\mathrm{Cr}-, \mathrm{Fe}-$, and $\mathrm{Ni}$-isotopes in the energy range 9 to $21 \mathrm{MeV}$. Jül-Report 3502, Forschungszentrum Jülich (1998).

11. Qaim, S. M., Stöcklin, G.: A systematic investigation of $(n, t)$ reactions at $14-15 \mathrm{MeV}$ on medium and heavy mass nuclei. J. Inorg. Nucl. Chem. 35, 19 (1973).

12. Qaim, S. M., Wölfle, R.: Triton emission in the interactions of fast neutrons with nuclei. Nucl. Phys. A 295, 150 (1978).

13. Herman, M., Capote, R., Carlson, B., Oblozinsky, P., Sin, M., Trkov, A., Zerkin, V.: EMPIRE-II, Nuclear Reaction Model Code, Version 2.19 (Lodi). International Atomic Energy Agency, Vienna (2005). http://www-nds.iaea.org/empire/index.html.

14. Bersillon, O.: Un programme de modele optique spherique. CEAN-2227, Centre d'Etudes de Bruyéres-le Châtel (1981).

15. Raynal, J.: Notes on ECIS. CEA-N-2772, Commissariat à l'Energie Atomique (1994).

16. Koning, A. J., Delaroche, J. P.: Local and global nucleon optical models from $1 \mathrm{keV}$ to $200 \mathrm{MeV}$. Nucl. Phys. A 713, 231 (2003).

17. McFadden, L., Satchler, G. R.: Optical model analysis of the scattering of 24.7 MeV alpha particles. Nucl. Phys. 84, 177 (1966).

18. Beták, E., Obložinský, P.: INDC(SLK)001. IAEA, Vienna (1993). 